\title{
Martu Ethnoarchaeology: \\ Foraging Ecology and the Marginal Value of Site Structure
}

\author{
Brian F. Codding ${ }^{\mathrm{a}}$, David W. Zeanah ${ }^{\mathrm{b}}$, Rebecca Bliege Bird ${ }^{\mathrm{c}}$, Christopher H. Parker ${ }^{\mathrm{a}}$, \\ Douglas W. Bird ${ }^{\mathrm{C}}$ \\ ${ }^{a}$ Department of Anthropology and Archaeological Center, University of Utah \\ ${ }^{b}$ Department of Anthropology, Sacramento State University \\ ${ }^{c}$ Department of Anthropology, Penn State University
}

\begin{abstract}
Archaeological investigations of hunter-gatherer site structure have remained largely descriptive, despite significant explanatory advancements by evolutionary approaches to foraging behavior and ecology. To date, calls to incorporate site structure studies within this behavioral ecological framework have largely been ignored. We suggest there is a clear explanation for this. At large spatial extents, human behavior is constrained by patterned ecological variability, as such, a general theory of behavior is likely to characterize key aspects of human decisions. At small spatial extents, human behavior is not constrained by patterned ecological variability, therefore, the human decisions that produce site structure should be driven by mechanical constraints or random variation. However, variation in site structure may be ecologically relevant inasmuch as it informs on landscape level variation in humanenvironment interactions. Drawing on ethnoarchaeological data collected in collaboration with Martu, Aboriginal foragers in Western Australia, here we test empirically-derived, mechanistic predictions on site size and material size sorting to show how these can inform theoretically-derived, adaptive predictions from the Marginal Value Theorem. Results show that site size increases with the number of occupants and hence, the amount of in-patch foraging competition, while size sorting increases with the duration of occupation and hence, in-patch residence time. Combined, these attributes of site structure can be used as proxies of foraging behavior to explain variability in overall foraging yields. With this approach, site structure can provide insights into foraging decisions that can be examined through a general theory of behavior.
\end{abstract}

Keywords: hunter-gatherers, site structure, marginal value theorem, behavioral ecology 


\section{Introduction}

Ecological and evolutionary approaches in hunter-gatherer archaeology continue to make tremendous strides toward explaining variation in subsistence (e.g., Broughton et al., 2011; Speth, 2010), settlement (e.g., Byrd et al., 2015; Winterhalder et al., 2010), technology (e.g., Surovell, 2012; Stevens and McElreath, 2015), storage (e.g., Morgan, 2012; Whelan et al., 2013), and demography (e.g., Kelly et al., 2013; Williams et al., 2015). But despite this progress, studies of site structure remain largely descriptive (e.g., Hill et al., 2011; Speth et al., 2012).

O'Connell (1995) made this same observation twenty years ago, noting the disparity between ethnoarchaeological studies of faunal remains and those of site structure. While the former were advancing successful explanatory frameworks, the latter remained stagnant. O'Connell suggested a simple, yet under-appreciated reason for this difference: studies of faunal remains were building on the foundations of a general theory which provided predictions a priori about how individuals are expected to behave in particular circumstances, but studies of site structure were based only on observations a posteriori without any guiding theory. Because the former predictions come from a general theory, they produce deductive inferences that should be true in all cases and therefore do not need to rely on direct ethnographic analogy in order to link ethnographic findings to the archaeological record. Because the later predictions come from empirical observations, they produce inductive inferences that must be tested in every case and cannot escape the problems of direct ethnographic analogy. It stands to reason then, for studies of site structure to move forward, they must begin with a general theory. Yet despite this seemingly simple fix, archaeologists guided by a general theory, such as behavioral ecology, have failed to meet O'Connell's challenge.
We argue that there is a clear and simple $\quad 46$ reason for this: because movement at small ${ }_{47}$ spatial extents should not significantly con- 48 strain behavior, patterning in site structure 49 will either be explained by simple mechanical $\quad 50$ parameters (e.g., human body size; Binford 51 1983) or random variation. However, move- 52 ment at larger spatial extents should be sig- 53 nificantly constrained by dynamic ecological 54 patterning, and as such, can be explained by 55 a general theory such as evolution by natu- 56 ral selection (e.g., Bird and O'Connell, 2006; 57 Codding and Bird, 2015; O'Connell, 1995). $\quad 58$ If this is true, then site structure can only 59 be informed by a general theory of behavior 60 inasmuch as site-level patterning can provide ${ }_{61}$ insight into larger, landscape scale decisions $\quad 62$ (including subsistence strategies, settlement ${ }_{63}$ and mobility; e.g., Binford 1980; Kent 1991). $\quad 64$

In an attempt to incorporate studies of site $\quad 65$ structure within a general theory of behavior, $\quad 66$ here we link two common empirically-derived, $\quad 67$ mechanistic predictions about site structure 68 to two theoretically-derived, adaptive pre- 69 dictions from a simple behavioral ecological 70 model known as the Marginal Value Theorem 71 (MVT, Charnov, 1976; Charnov and Parker, 72 1995). Then we test these predictions with 73 ethnoarchaeological data collected in collabo- $\quad 74$ ration with Martu, an Aboriginal population 75 who reside in and have native title over their $\quad 76$ ancestral estates in Western Australia.

\section{Predictions}

Behavioral ecological archaeologists focus 79 on developing adaptive explanations of past human decisions that can be tested with material remains (Bird and O'Connell, 2006; Codding and Bird, 2015). As outlined by Tinbergen (1963), adaptive explanations examine the evolutionary function of behaviors in how they contribute to survival and reproductive success. But this is only one of four levels of explanations commonly employed to 
explain behavior. The others include mechanistic explanations, which focus on proximate causal factors, ontogenetic explanations, which focus on understanding how behaviors develop through the life course, and phylogenetic explanations which focus on how a particular behavioral trait evolved within a linage (Tinbergen, 1963). As discussed above, predictions about site structure typically fall within the mechanistic level. Here we attempt to link two of these mechanistic proposals to adaptive predictions derived from the MVT.

\subsection{Mechanistic Predictions}

Several mechanistic "rules" of site structure have been proposed and tested with ethnographic or ethnoarchaeological data over the last seventy-five years (reviews in David and Kramer, 2001). Two of these are of particular relevance to the Marginal Value Theorem. These involve site size and the degree of size sorting.

First, because multiple people cannot occupy the same space while completing domestic tasks, the size of a site should increase with the number of occupants, of course, with all else being equal (e.g., tasks undertaken, kin-based residential rules, need for defense, etc.). This pattern was first described and tested by Cook and Treganza (1950) and subsequently confirmed by prominent ethnoarchaeologists working across the world (e.g., Yellen, 1977).

Second, because small discarded materials are likely to be dropped in situ (e.g., Binford, 1978a) and because large discarded materials will hinder ongoing activities within a site, people are likely to move larger items away from central activity areas (Hayden and Cannon, 1983) while overlooking smaller items. This causes significant size sorting wherein larger materials will tend to be more dispersed and smaller materials will tend to remain near the point of primary deposition
(O'Connell, 1987). Importantly, the degree of 133 size sorting should be contingent on the dura- ${ }_{134}$ tion of occupation: as individuals stay longer 135 at a site, it becomes worthwhile to remove ob- ${ }_{136}$ trusive waste (O'Connell, 1987, 100); at least ${ }_{137}$ up to some threshold where it becomes less 138 costly to move to a new camp and start over 139 (O'Connell, 1977). The amount of small ma- ${ }_{140}$ terial remaining in situ should decrease pro- ${ }_{141}$ portionally with the efficiency of the cleaning $\quad 142$ technology (O'Connell, 1987, 92). ${ }_{143}$

These predictions suggest that with 144 hunter-gatherer camps, the size of a site 145 should be a reliable indicator of the number ${ }_{146}$ of people (and number of active foragers if ${ }_{147}$ proportional to the number of people) who ${ }_{148}$ occupied it and the degree of size sorting 149 should provide information on the duration 150 of site occupation. Site size may also increase 151 with the actual (Yellen, 1977) or anticipated ${ }_{152}$ (e.g., Kent, 1992; Kent and Vierich, 1989) ${ }_{153}$ duration of occupation, which may present 154 a potential confound, but this is something 155 that can be examined empirically. 156

\subsection{Adaptive Predictions}

Based on the premise that natural selection $\quad 158$ should favor optimal food acquisition strate- ${ }_{159}$ gies, the MVT provides a framework to un- ${ }_{160}$ derstand how long a forager should search for ${ }_{161}$ resources within a discrete patch before leav- ${ }_{162}$ ing to travel to a neighboring patch (Charnov, ${ }_{163}$ 1976; Charnov and Parker, 1995). Because a ${ }_{164}$ forager depresses the abundance of resources 165 by removing them (Charnov et al., 1976), the ${ }_{166}$ energy acquired within a patch diminishes as ${ }_{167}$ a function of the time spent in the patch (Fig- ${ }_{168}$ ure 1). Following Charnov and Parker (1995), 169 the cumulative energy gain $\left(G_{t}\right)$ within a 170 patch can be described as:

$$
G_{t}=G_{m}[1-\exp (-c \cdot t)]
$$

where $t$ is the in-patch (foraging) time, $G_{m} \quad 172$ is amount of energy originally in the patch 173 
(i.e., pre-foraging) and $c$ is the rate at which acquired energy reaches $G_{m}$. Because the cumulative gain diminishes over time, there should be an optimal threshold at which a forager should leave the patch and travel to another patch. Charnov and Parker (1995) approximate the optimal leave time $\left(t^{*}\right)$ as:

$$
t^{*}=\frac{\left(\frac{c \cdot \mu+2}{c \cdot \mu+1}\right) \log (c \cdot \mu+1)}{c}
$$

where $\mu$ is the travel distance to the next nearest patch. The depletion rate $(c)$ should be inversely proportional to the available energy in the patch $\left(G_{m}\right)$ as a result of the increased time required to search the patch (if prey density remains constant; Charnov and Parker 1995). In other words, larger patches have more resources, but take longer to search.

This model provides a clear framework to predict how the number of foragers within a patch and patch residence time should interact to the determine the amount of energy acquired per capita. Holding the available energy within a patch constant, when there are more people within a patch, per capita gains will be lower (divided between more people) and less time will be spent searching within the patch. Holding the number of foragers constant, when a patch has more energy, individuals will spend more time searching the patch, which will increase the optimal patch residence time. Figure 1 illustrates these predictions with hypothetical scenarios.

While this model is specific to environmental situations where resources are patchily distributed, it holds for humans even if patches are homogeneous because humans are central place foragers (Orians and Pearson, 1979) who return acquired food to a home base. As such, human foraging segments environments into catchments around central places.

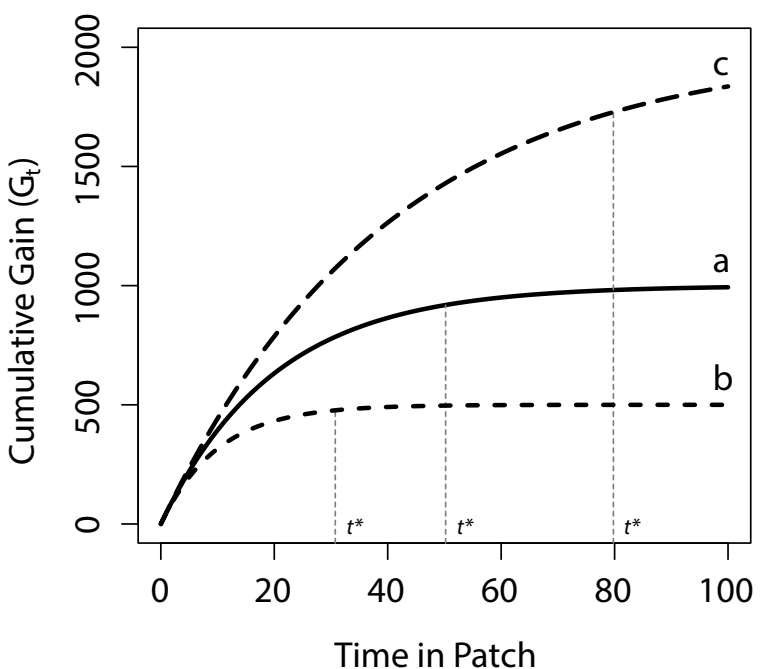

Figure 1: Graphical representation of the Marginal Value Theorem after Charnov and Parker (1995). From a baseline (a; $G_{m}=1000, c=0.5$ ), doubling the number of foragers in the patch should halve the energy acquired per capita, halve the time required to search the patch and decrease the optimal patch residence time (b; $G_{m}=500, c=1.0$ ), while doubling the energy available in the patch should increase the time required to search the patch (if prey density is constant) and increase the optimal patch residence time $\left(\mathrm{c} ; G_{m}=2000, c=0.25\right)$. Note, travel time to the next nearest patch is held constant $(\mu=175)$.

\subsection{Summary of Predictions}

If (P1) site size increases with the number of foragers and (P2) size sorting increases with the duration of site occupation, then ${ }_{217}$ these attributes of site structure may be used ${ }_{218}$ as proxies for the number of foragers within a $\quad 219$ patch and patch residence time, respectively. $\quad 220$ If so, then per capita foraging returns should 221 (P3) decrease with site size and (P4) increase 222 with size sorting. If these findings hold, these ${ }_{223}$ elements of site structure may be incorpo- 224 rated within this general theory of behavior 225 to help explain variability in foraging behav- 226 ior at larger spatial extents where decisions 227 are constrained by patterned environmental 228 variation.

Following the strategy outlined in Codding 230 and Bird (2015, 11-12), we test these four 231 predictions using ethnographic and ethnoar- 232 
chaeological data collected in collaboration with Martu.

\section{Ethnographic Background}

Martu, also known as Mardu or Mardujarra, are part-time foragers who live on and have native title over their traditional estates (sensu Stanner, 1965) in Western Australia. Within the climatologically-defined Arid Zone and the Western Desert cultural area, the Martu homeland is centered on the Karlamilyi River, expanding west to the Pilbara, northeast to the Percival Lakes and south to Lake Disappointment (Figure 2). The Native Title Determination Area includes many of the estates belonging to Kartujarra, Manyjilyjarra, Warnman dialect speakers, though the core Warnman estates around Karlamilyi were retained by the Australian Government as a National Park.

Prior to European contact in the midtwentieth century, Martu were full-time foragers. Subsistence strategies varied by gender: men focused on larger hunted game, both men and women pursued smaller game, and women focused on key plant resources (Tonkinson, 1993; Veth and Walsh, 1988; Walsh, 1987, 2008). Group structure was centered on female kin who formed cooperative partnerships (Scelza and Bliege Bird, 2008) and provided the majority of foraged foods (Tonkinson, 1993, 43-45; see also Gould 1969). When successful, men's hunting contributed significant proportions of meat to the the diet, but since success was rare, men's production was highly variable (Tonkinson, 1993, 43-45). Children foraged as well, sometimes helping to gather fruits or hunt small game, with the proceeds of their labor often consumed on the spot (Tonkinson, 1993, 47).

Many of these patterns continue today within a hybrid economy (sensu Altman, 2001) wherein hunting and gathering for wild foods remains one of the best economic al- ternatives (Codding et al., 2016). Men tend 276 to focus on larger prey which comes with a 277 higher risk of acquisition failure, while women 278 focus on smaller, more reliable resources 279 (Bliege Bird and Bird, 2008; Bliege Bird 280 et al., 2009; Codding et al., 2011). Men's 281 hunting occasionally contributes significantly 282 to daily calories (Bliege Bird et al., 2009; 283 Codding et al., 2011), but given the high risk ${ }_{284}$ of failure, some aspects of men's hunting may 285 be driven in part by traditional forms of so- 286 cial and ritual competition rather than food ${ }_{287}$ (Bird and Bliege Bird, 2010). Such compe- 288 tition may have real material outcomes, in- 289 cluding lowering the age of marriage for off- 290 spring (Scelza, 2010). Women's cooperative 291 partnerships remain extremely important for 292 both resource acquisition (Bliege Bird et al., 293 2012b) and childcare (Scelza, 2009). The 294 reliability of women's hunting is increased 295 through the use of anthropogenic fire, which 296 feeds back to structure broad and varied 297 environmental patterns (Bird et al., 2005; 298 Bliege Bird et al., 2008, 2012a, 2013; Codding 299 et al., 2014; Zeanah et al., 2015). Children 300 also remain active foragers, sometimes con- 301 tributing significant amounts of food to their 302 daily diet (Bird and Bliege Bird, 2005) and 303 overall, foraging remains an important source 304 of provisioned foods for dependents (Codding 305 et al., 2016).

One major aspect of foraging that has 307 changed centers on mobility. While tradi- 308 tionally charactered as high mobility foragers 309 (sensu Binford, 1980) who needed to move 310 once local resources were diminished (Tonk- 311 inson, 1993), today Martu use vehicles to op- 312 erate logistically (sensu Binford, 1980) from 313 a central community. This logistic mobility 314 facilitates a specific type of temporary settle- 315 ment called a dinner-time camps (see, e.g., 316 Meehan, 1982).

3
9
11
12
13
17
17
17




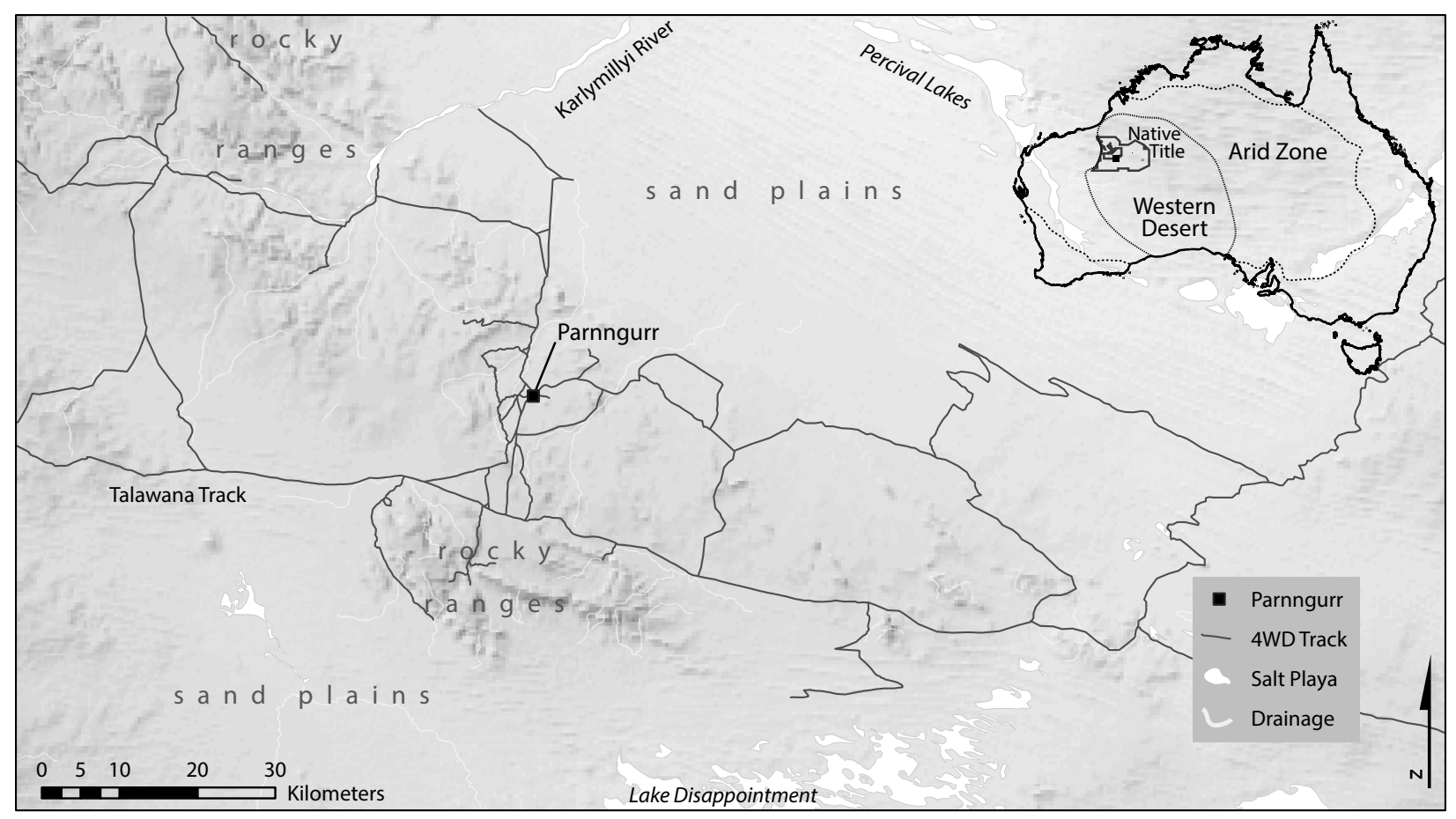

Figure 2: Areas surrounding Parnngurr within Martu Native Title area (insert).

\subsection{Dinner-Time Camp Foraging}

A foraging party will leave the community and travel to a named hunt region where they will establish a dinner-time camp. As the central locus of contemporary foraging, these dinner-time camps are extremely important as a focal node of economic production and social formation. While some dinner-time camps may be occupied repeatedly, most are used only once and produce very ephemeral material signatures. Once foragers arrive at the camp, some may stay behind to collect wood and build a fire, while others travel out in search of wild resources. With most foraging activities, individuals travel out from the dinner-time camp on foot and begin searching for target prey. Two of the most common prey types are sand monitor lizards (also known as goanna, Varanus gouldii, or parnajalpa) and hill kangaroo (also known as euro, Macropus robustus, or kirti-kirti). The former are found throughout the vast sand plains that blanket the area while the latter are home in rocky ranges that dot the land- ${ }_{341}$ scape (see Figure 2). Often these habitats oc- 342 cur side-by-side, allowing individual hunters 343 to walk out on foot from a centrally lo- 344 cated dinner-time camp and pursue either re- 345 source. While there is overlap in women's and 346 men's activities (see above), often men walk 347 out in search of hill kangaroo while women 348 walk out onto the sand plain in search of 349 monitor lizards (Bliege Bird and Bird, 2008; 350 Bliege Bird et al., 2009; Codding et al., 2011). 351 Because monitor lizards are a much more re- 352 liable resource (Codding et al., 2011), they 353 provide the bulk of acquired calories returned 354 to dinner-time camps (Bliege Bird and Bird, 355 2008).

We refer to the total time an individ- ${ }_{357}$ ual spends searching for and pursuing re- 358 sources within a patch or foraging activity as 359 a foraging bout. Individuals rarely engage in 360 more than one foraging bout per day, making 361 Martu dinner-time camp foraging not com- 362 pletely consistent with the original formula- 363 
tion of the the MVT, which was designed to evaluate the optimal time a forager should spend in a patch before leaving to travel to another patch. However, the model is still applicable in this case. Since foragers only undertake one bout per day, and the decision to leave a patch is contingent on an individuals assessment of opportunity costs, the general MVT framework still holds. Once an individual decides their foraging bout is over, they return to the dinner-time camp where everyone will process, cook and share their foods based on traditional practices (e.g., Bird and Bliege Bird, 2010).

Unlike more permanent camps from precontact times (e.g., Gould, 1977), dinnertime camps rarely have any formal structures or features beyond the roasting hearth. Hearths are the focus of activities at dinnertime camps. With smaller prey, like monitor lizards, the individual hunter is generally responsible for processing and cooking their catch. This involves removing the intestines, singeing the skin in hot flames, digging an appropriate sized pit, lining the pit with hot coals, burying the prey in hot sand, and placing hot coals and burning wood on top of the roasting pit. With larger prey, like hill kangaroo, it is the responsibility of an available relative, preferably a mother's brother (e.g., Gould, 1967), to take over processing and cooking. The general procedure is the same as with small prey, though with the disemboweling effort and the size roasting pit scaled proportionately to the size of the animal (see also Bird and Bliege Bird, 2010; O'Connell and Marshall, 1989). Once in the ground, cooking is passive and time is generally passed with conversations about the hunt, the impending meal, and life in general. Because they are only used once, hearths themselves have relatively low fidelity: ethnoarchaeological investigations reveal that while they are still identifiable eight years after creation, they are more subtle and diffuse (Codding, 2012); we expect they would not be identifiable for more than one or two decades.

Once cooking is complete, prey are distributed among all who are present (see Bird and Bliege Bird, 2010; Bird and Power, 2015; Bliege Bird et al., 2012b; Codding, 2012, also Gould 1967 for more details on food sharing). Smaller prey are generally distributed whole while larger prey are disarticulated according to traditional law (see Bird and Bliege Bird, 2010). As individuals finish consuming their share, some bones are dropped in place while others are gently tossed to the side. In some ways this should produce material patterning similar to Binford's (1978a) "drop and toss" zones, which may result in size sorting (O'Connell, 1987). Once everyone has had their fill, the foraging party packs up into the vehicles and returns to the community. Most often all wild foods are consumed at the dinner-time camp, but when harvests are abundant, remains may be taken back to the community for later consumption of further distribution.

\section{Methods}

\subsection{Data Collection}

This study is part of a long-term ethnographic collaboration with Martu that began in 2000. Intensive quantitative ethnographic data used here were collected from 2000-2010 and include 1806 focal-individual follows (sensu Altmann, 1974) across 344 discrete dinner-time camps. The main unit of analysis is the individual foraging bout: the total time spent on search and pursuit within an activity or patch and the total energy acquired during that time. Greater detail on data collection methods and on summary analyses of these data can be found elsewhere (e.g., Bird et al., 2009; Bliege Bird and Bird, 2008; Bliege Bird et al., 2009, 2012b; Codding et al., 2010, 2011, 2014). 
Ethnoarchaeological investigations focused on a representative sample of dinner-time camps where either sand monitor or hill kangaroo hunting took place. Of the 344 discrete dinner-time camps, individuals targeted either sand monitors or hill kangaroo at 196 camps and twelve of these were selected for ethnoarchaeological investigations. Quantitative foraging data from this ethnoarchaeological subset do not differ significantly from the main foraging dataset, indicating that it is a representative sample (Codding, 2012). Ethnoarchaeological excavations were undertaken between 2009-2010. Researchers revisited the selected dinner-time camps and established a grid centered on the hearth dividing the entire site into $1-\mathrm{x}-1-\mathrm{m}$ units. Soils were excavated with shovel scrapes within each $1-\mathrm{x}-1-\mathrm{m}$ unit that continued until sterile sand (typically $<5 \mathrm{~cm}$ ). Materials were screened through nested $6-\mathrm{mm}(1 / 4$-in) and 3 -mm (1/8-in) mesh, providing a large and a small fraction that could be used to examine variation in size sorting across the site. Analyses focused on faunal material. Greater detail on these methods and additional analyses are reported in Codding (2012).

From these combined datasets, we extract six variables to test the four main predictions listed above: site size, the number of site occupants (and how many of those are foragers), the degree of size sorting, the duration of site occupation and both the median and mean per capita monitor lizard harvest. Site size is calculated as the number of $1-\mathrm{x}-$ 1-m units from which bones were recovered. The number of site occupants and the number of foragers are tallied from quantitative observations. Size sorting is calculated as the standard distance deviation (see below) of the 6-mm fraction relative to the $3-\mathrm{mm}$ fraction. The duration of active site occupation (or occupation time) is the total person minutes at the site excluding time spent foraging. This should measure the cumulative impact of hu- man activity at the site, which we expect will ${ }_{497}$ lead to greater size sorting. Because the dis- ${ }_{498}$ tribution of monitor harvest (kcal per bout) ${ }_{499}$ is skewed (see Codding et al. 2010), mean and 500 median values per camp may provide a signif- 501 icantly different result. As such, we run anal- 502 yses using both mean and median per capita 503 harvest size (kcals) per bout.

\subsection{Data Analysis}

505

All analyses are performed in the $\mathrm{R}$ envi- 506 ronment (R Core Team, 2015). Here we re- 507 view our approach to estimating size sorting 508 and to hypothesis testing.

The dispersion of bone fragments was quantified for each site as the standard distance deviation (or standard distance). This was implemented in the aspace library (Bui et al., 2012) using the number of bones recovered from each 1-x-1-m unit for each recovery method (fine and coarse grained mesh). For visualization purposes, standard deviation ellipses were also calculated for each recovery method. Size sorting was then calculated as the difference in standard distance between the $3-\mathrm{mm}$ and $6-\mathrm{mm}$ factions so that the more positive numbers equal greater dispersion of larger bone fragments relative to smaller fragments.

Tests of predictions rely on linear mod- 525 els. However, ordinary least squares regres- 526 sion models are inappropriate for this analy- 527 sis because the independent (response) vari- ${ }_{528}$ ables are either heavily skewed (i.e., not nor- 529 mally distributed) or not continuous (e.g., $\quad 530$ count data). Instead of turning to rank- 531 ordered non-parametric statistics, which re- 532 duce variation by converting continuous or 533 count data to ordinal numbers, we rely on 534 generalized linear models (GLM) designed to 535 extend Gaussian linear models by specifying 536 a distribution and link function appropriate 537 to the data (Faraway, 2006; R Core Team, ${ }_{538}$ 2015). Unless otherwise noted in the text, 539 
we rely on models with a Poisson distribution, log link and quasi-likelihood estimation. Poisson-log GLMs with quasi-likelihood estimation are appropriate for our data which are either count (e.g., number of occupants) or count-like (e.g., number of calories), and non-normally distributed. ${ }^{1}$ Through qasilikelihood estimation, these models also avoid over-dispersion by relaxing the assumption that the mean and variance are equal. As with GLMs generally, qusi-likelihood Poisson models are common in ecology (e.g, Ohara and Kotze, 2010) and their application is growing in archaeology (e.g., Shennan et al., 2013). Model results report the Y-intercept, estimated change in the dependent (y) variable with a change in the independent $(\mathrm{x})$ variable, $\alpha$ or $p$-value associated with the independent variable (Ind. $p$ ), log-likelihood r-square value $\left(R_{L}^{2}\right)$ which is the proportion of deviance explained by the inclusion of the independent (predictor) variable, and the $p$ value from a likelihood ratio test (LRT $p$ ) which indicates whether or not the inclusion of the predictor variable significantly improves the model fit compared to the null model. Because these models incorporate a log-link, y-intercepts and estimates are reported as the exponent for interpretation.

\footnotetext{
${ }^{1}$ Results of Shapiro-Wilk Normality Test reveal that the dependent (response) variables are not normally distributed: number of occupants $(W=$ $0.64, p<0.0001)$, the number of foragers $(W=$ $0.85, p=0.0408)$, occupation time $(W=0.59, p<$ $0.0001)$, foraging time $(W=0.81, p=0.0138)$, median harvest $(W=0.86, p=0.0893)$, and mean harvest $(W=0.82, p=0.0359)$. While the median sand monitor harvest only departs from normal with marginal significance $(p<0.1)$, it is sampled from a larger distribution of sand monitor hunts that is highly skewed $(W=0.84, p<0.0001)$.
}

\section{Results}

Before testing the specific predictions, 570 analyses must confirm that monitor lizard 571 foraging follows the general framework pro- 572 posed by the marginal value theorem and con- 573 firm that size sorting is present at these sites. $\quad 574$

As shown in Figure 3, across 166 camps 575 at which at least one individual went sand 576 monitor hunting, the mean per capita har- 577 vest (E, kcal) varies significantly as a func- 578 tion of the time spent in patch $(\mathrm{T}, \mathrm{min})$ when $\quad{ }_{579}$ fit with a normal-log linear model $\left(R_{L}^{2}=580\right.$ $0.23, p<0.0001)$. This can be approxi- 581 mated by a diminishing returns curve follow- 582 ing the $\operatorname{MVT}\left(G_{m}=3000, c=0.007\right)$. This ${ }_{583}$ is also true for the median per capita har- 584 vest $\left(R_{L}^{2}=0.19, p<0.0001 ; G_{m}=2500, c=585\right.$ $0.009)$. These findings suggest that monitor 586 lizard hunting, and the representative sample 587 of ethnoarchaeological camps, should provide 588 a viable window into MVT dynamics.

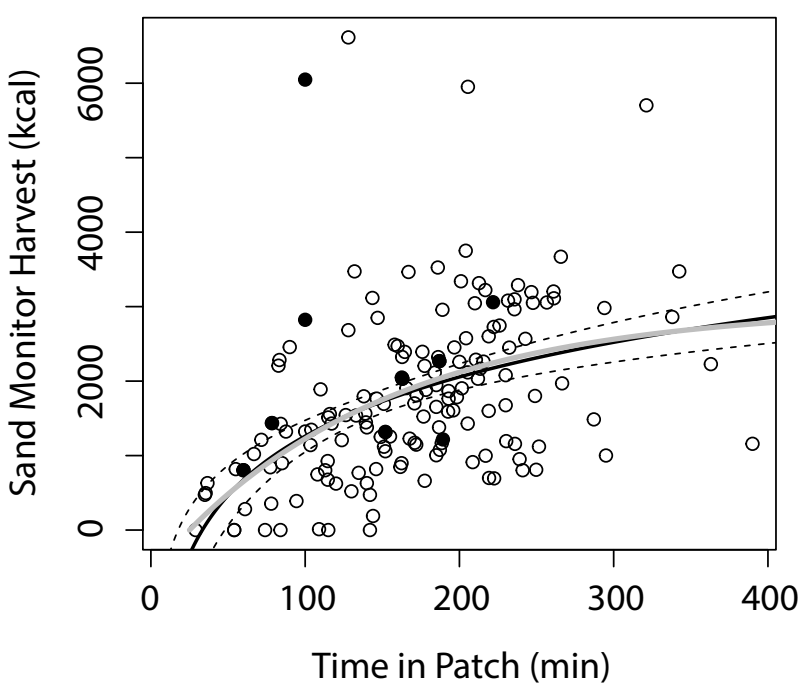

Figure 3: Mean per capita monitor lizard harvest (E, kcal) as a function of the time spent in patch ( $\mathrm{T}$, min) across 166 sand monitor hunting camps shown with a normal-log GLM fit (black solid line with dashed $95 \%$ confidence intervals) and an approximate diminishing returns curve following the MVT (gray solid line). Ethnoarchaeological camps shown as solid black points.

Size sorting was calculated from bone 590 

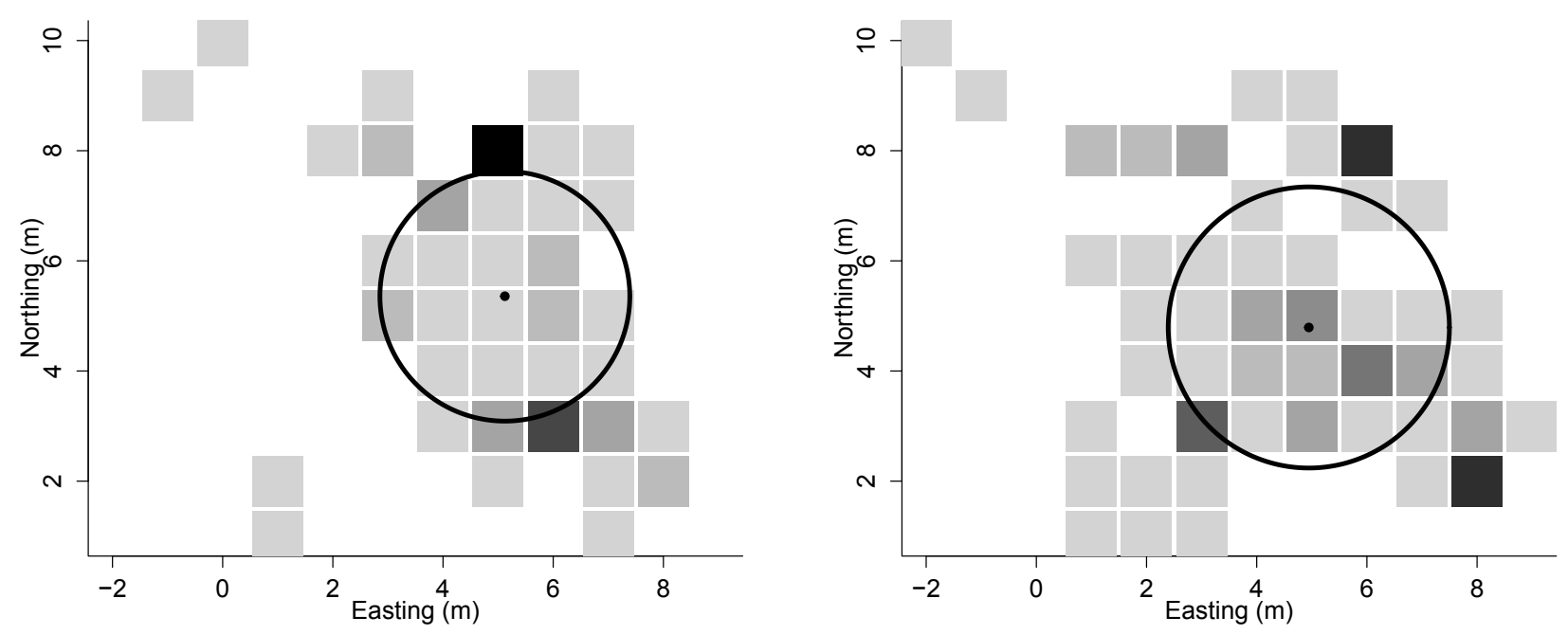

Figure 4: Distribution of recovered bones from 3-mm mesh (left) and 6-mm mesh (right) across 1-x-1-m units superimposed for all 11 excavated ethnoarchaeological camps. Relative density of recovered bones per unit illustrated in gray-scale from none in white to maximum (43 and 33 respectively) in black. Standard deviation ellipses (circles) indicate that larger bone fragments are more dispersed overall. The center of dispersion (points) for both recovery methods remains close to hearth locations (located at 5.5m North, $5.5 \mathrm{~m}$ East), with the 3 -mm fraction being slightly closer.

counts per unit, which ranged from zero to 33 in the $6-\mathrm{mm}$ fraction and from zero to 43 in the $3-\mathrm{mm}$ fraction. Data on bone dispersion is available for ten of the twelve sites and monitor lizard hunting occurred at nine of these. The two sites for which dispersion data is unavailable include one where only a failed kangaroo hunt occurred, producing no material signature other than a hearth, and one where only a single bone was recovered, from which it is impossible to calculate dispersion. Of the remaining ten sites, larger bone fragments recovered from the coarse grained (6$\mathrm{mm}$ ) fraction are generally more dispersed than smaller bone fragments recovered from the fine grained (3-mm) fraction. Including all ten sites, the difference in dispersion between ranges from -0.85 to 0.41 , with nonnegative value for the mass of the distribution ( 7 out of 10 sites; IQR $=-0.12-0.22$, median=0.032). Excluding the one site where monitor lizard hunting did not occur, dispersion across the nine remaining sites confirms that larger material tends to be more dispersed than smaller material: the differ- ${ }_{615}$ ence in standard distance ranges from $-0.27{ }_{616}$ to $0.41(\mathrm{IQR}=0.00-0.26$, median $=0.06)$ with ${ }_{617}$ only two sites exhibiting negative size sort- 618 ing. These findings illustrate that significant 619 size sorting generally occurs even at these ${ }_{620}$ ephemeral, short-term dinner-time camps. $\quad{ }_{621}$

These results confirm that the foraging 622 data examined here does conform to the ${ }_{623}$ MVT assumptions, and that size sorting is 624 occurring at these sampled camps. This al- 625 lows analyses to move forward with the exam- 626 ination of each of the mechanistic and adap- ${ }_{627}$ tive predictions proposed above.

\subsection{Prediction 1: the number of foragers should increase with site size}

629

Based on the simple mechanics of how hu- 631 mans occupy space, the number of site oc- ${ }_{632}$ cupants and (if proportional) the number of ${ }_{633}$ foragers should increase as a function of site ${ }_{634}$ size. Across the eleven excavated sites, the 635 number of site occupants and the number of ${ }_{636}$ active foragers significantly increase with site ${ }_{637}$ size (Table 1, Figure 5a). This confirms the ${ }_{638}$ 

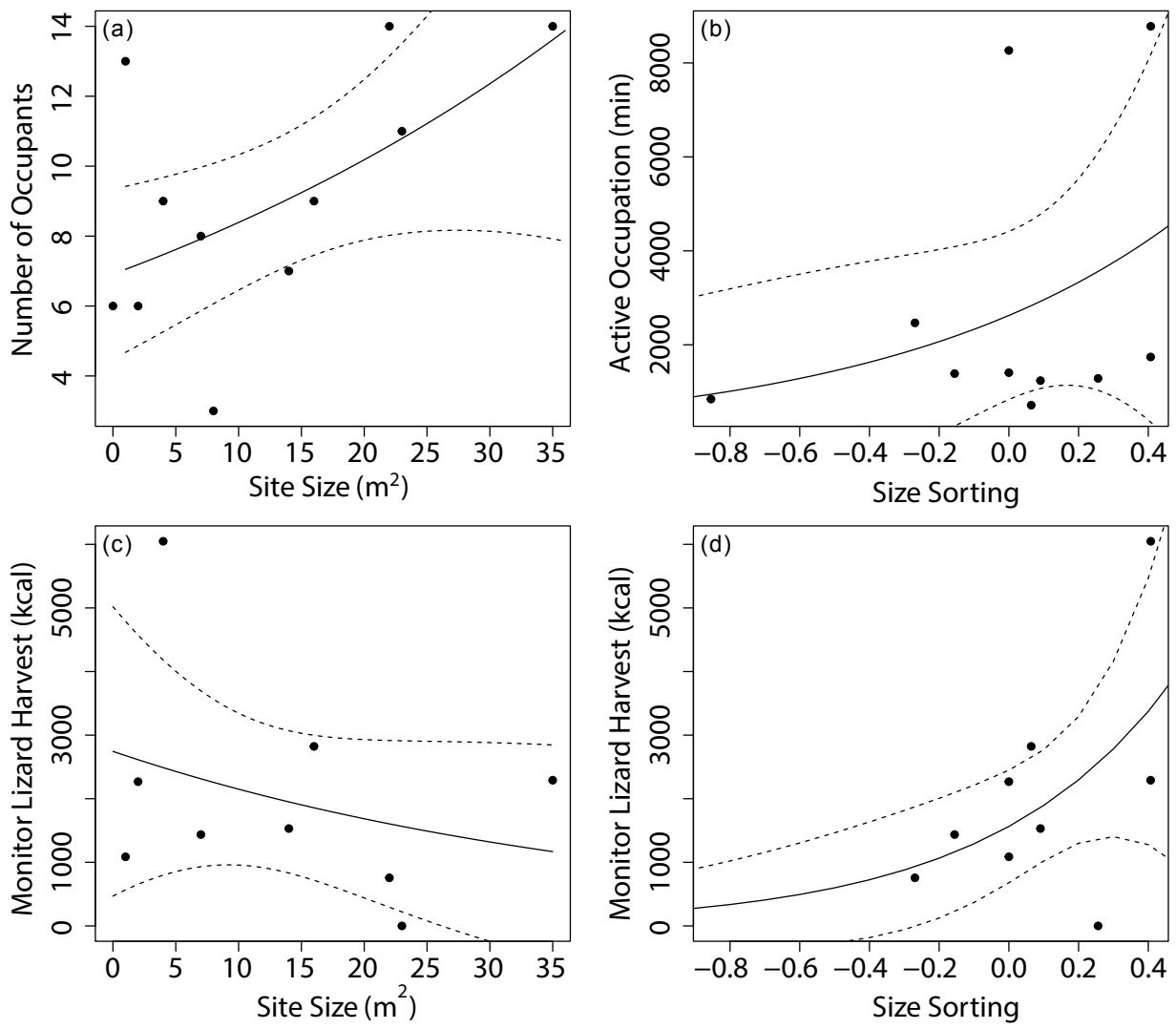

Figure 5: Plots and model fits summarizing results from the four main predictions. (a, P1) Number of site occupants as a function of site size $\left(\mathrm{m}^{2}\right)$. (b, P2) Duration of active site occupation as a function of size sorting. (c, P3) Median monitor lizard harvest (kcals) as a function of site size and (d, P4) as a function of size sorting. Confidence intervals show the standard error $(95 \%)$ of the model fit. See Table 1 for details.

first mechanistic prediction and suggests that site size may be a useful proxy of foraging yields.

\subsection{Prediction 2: the duration of occupation should increase with size sorting}

If material becomes more dispersed as a function of more time spent a the site, then the duration of occupation should increase with degree of size sorting. Across the ten sites for which size sorting data was available, the active occupation time and the sum time spent hunting monitor lizards increases as a function of the difference in dispersion between large and small bone fragments (Figure $5 \mathrm{~b})$. While overall the models are a significant improvement over a null model, the effect of each independent variable is not sta- tistically significant (Table 1). These find- 656 ings suggest that size sorting may be a rough ${ }_{657}$ proxy for the amount of time individuals 658 spend at a site and the amount of time spent 659 foraging, but that the effect may sometimes 660 be due to chance.

\subsection{Prediction 3: overall foraging yields 662 should decrease with site size}

Based on theoretical insights from the 664 MVT, more people, occupying larger sites, 665 should cause greater in-patch competition ${ }_{666}$ and result in lower per capita yields. The ${ }_{667}$ results show that this generally holds true: ${ }_{668}$ monitor lizard harvests decline as site size in- ${ }_{669}$ creases (Figure 5c). But the effect is only sig- 670 nificant inasmuch as the inclusion of site size 671 improves the prediction of monitor lizard re- ${ }^{672}$ 
Table 1: Summary of bivariate model results testing each of the four predictions.

\begin{tabular}{cllrrrrr}
\hline Pred. & Dep Var. & Ind. Var. & Y-intcp. & Est. & Ind. $p$ & $R_{L}^{2}$ & LRT $p^{*}$ \\
\hline 1 & \# of Occupants & Site Size & 7.05 & 1.02 & 0.0696 & 0.31 & 0.0314 \\
1 & \# of Foragers & Site Size & 2.71 & 1.03 & 0.0517 & 0.35 & 0.0111 \\
2 & Occupation Time & Size Sorting & 2624.91 & 3.29 & 0.3310 & 0.16 & $<0.0001$ \\
2 & Foraging Time & Size Sorting & 384.87 & 3.88 & 0.3690 & 0.12 & $<0.0001$ \\
3 & Median Harvest & Site Size & 2744.10 & -1.02 & 0.4180 & 0.10 & $<0.0001$ \\
3 & Mean Harvest & Site Size & 2419.22 & -1.00 & 0.9090 & $<0.01$ & $<0.0001$ \\
4 & Median Harvest & Size Sorting & 1563.53 & 6.83 & 0.1060 & 0.28 & $<0.0001$ \\
4 & Mean Harvest & Size Sorting & 1879.76 & 5.34 & 0.0768 & 0.38 & $<0.0001$ \\
\hline
\end{tabular}

*Note: LRT $p$-values report the results of a likelihood ratio test, which indicates if the inclusion of the independent variable significantly improves the model fit compared to a null model.

turns when compared to a null model ( $p<$ 0.0001), with any independent effects of site size likely due to chance (Table 1). Moreover, this is not a very robust association, with site size explaining only $10 \%$ of deviance in median returns and less than $1 \%$ in mean returns.

\subsection{Prediction 4: overall foraging yields should increase with size sorting}

Foragers should stay longer in higher quality patches, which should result in greater size sorting and higher per capita returns. The data support this prediction, showing that mean and median harvests increase with the degree of size sorting (Figure 5d). Size sorting explains $28 \%$ of the deviance in median monitor lizard harvest and 38\% in mean harvest. Though while the inclusion of the independent variable improves each model significantly $(p \leq 0.0001)$, the effect of each independent variable is only marginally significant $(p \leq 0.1$; Table 1$)$.

Overall, these findings roughly support the predictions, showing that per capita foraging yields decrease with site size and increase with size sorting. However, while the results do move in the predicted directions, the effects are less robust than would be ideal. These limited effects may result from the interactions between the number of occupants and patch duration.

\subsection{Interactive Effects}

To deal with the potential interactive effects of the number of foragers and the duration of occupation (and their material correlates) on overall returns, we analyze these in a series of multivariate models. Combined, the number of foragers and the dura- 7 tion of occupation accurately predict median 711 and mean monitor lizard harvest (Table 2, 712 Figure 6). This is especially the case with me- ${ }_{713}$ dian harvests, where each independent vari- 714 able is marginally significant and the overall 715 model is highly significant explaining $58 \%$ of 716 the deviance. These patterns are consistent 717 into the material record: site size and the 718 degree of size sorting also accurately predict 719 monitor lizard harvest (Table 2, Figure 6). ${ }_{720}$ Again, these patterns are more robust with 721 median returns, of which site size and size 722 sorting have a marginally significant and sig- 723 nificant effect respectively, together explain- 724 ing $50 \%$ of the deviance. In both cases, these ${ }_{725}$ findings are more robust with median than 726 mean returns and indicate that size sorting 727 might be a more significant predictor of over- 728 all returns than site size. $\quad 729$

\section{Discussion}

730

At a descriptive level, these findings con- 731 firm previous results illustrating that site size 732 

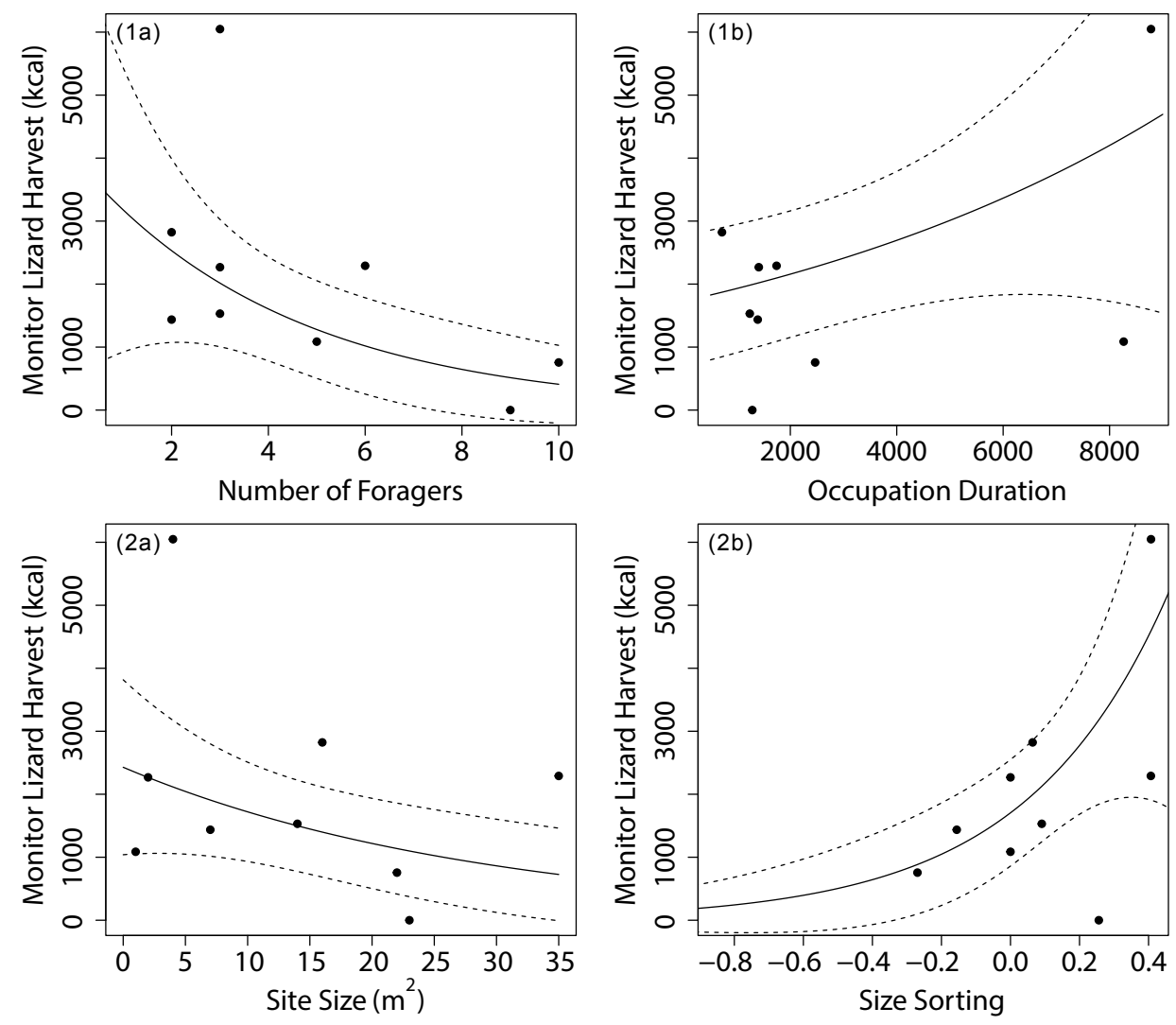

Figure 6: Plots summarizing two multivariate models: the first (top row) examining the combined effect of (1a) the number of foragers and (1b) the duration of site occupation (min) on median per capita monitor lizard harvest (E, kcals); the second (bottom row) examining the combined effect of $(2 \mathrm{a})$ site size $\left(m^{2}\right)$ and (2b) size sorting on median per capita monitor lizard harvest (E, kcals). Model fits illustrate the effect of each independent variable while holding the other constant at its median value. Confidence intervals show the standard error (95\%) of the model fit. See Table 2 for details.

tends to increase with the number of occupants (e.g., Yellen, 1977) and that smaller artifacts are more likely to remain in their primary context than are larger objects (e.g., O'Connell, 1987). The later finding is quite remarkable given that these are ephemeral, short-term camps but size sorting is still present in seven of the nine focal sites.

At an explanatory level, these findings illustrate that aspects of site structure may be useful proxies of larger-scale ecological interactions that lead to variation in foraging yields. Where foraging follows the assumptions of the MVT, the combined interaction of site size and size sorting should be indicative of overall wild food harvests. Although we do not want to over-interpret our empiri- 749 cal findings. Our bivariate model results are 750 less robust than would be ideal, with rela- 751 tively high p-values suggesting that some of 752 these results may be false positives (Type I er- 753 rors). Nonetheless, all of the trends do move 754 in the predicted direction, which is encourag- 755 ing in itself given the relatively small size of 756 the ethnoarchaeological dataset and all of the 757 noise expected in these parameters. 758

The limitations of these bivariate models 759 may also result from the interactive effects 760 of site size (as a proxy of foraging competi- 761 tion) and size sorting (as a proxy of patch 762 quality). When combined in a multivariate 763 model to control for these interactions, the 764 
Table 2: Summary of multivariate model results examining the combined effect of each independent variable on mean and median monitor lizard harvest size (kcal) per bout.

\begin{tabular}{llrrrrr}
\hline Dep. Var. & Ind. Var. & Y-intcp. & Est. & Ind. $p$ & $R_{L}^{2}$ & LRT $p^{*}$ \\
\hline \multirow{2}{*}{ Median Harvest } & Whole Model & 3418.65 & - & - & 0.58 & $<0.0001$ \\
& \# Foragers & - & -0.80 & 0.0829 & - & - \\
& Occupation Time & - & 1.00 & 0.0930 & - & - \\
Mean Harvest & Whole Model & 2342.56 & - & - & 0.25 & $<0.0001$ \\
& \# Foragers & - & -0.94 & 0.4950 & - & - \\
& Occupation Time & - & 1.00 & 0.2420 & - & - \\
Median Harvest & Whole Model & 2245.96 & - & - & 0.50 & $<0.0001$ \\
& Site Size & - & -1.04 & 0.1059 & - & - \\
& Size Sorting & - & 11.41 & 0.0399 & - & - \\
Mean Harvest & Whole Model & 2187.05 & - & - & 0.44 & $<0.0001$ \\
& Site Size & - & -1.01 & 0.4383 & - & - \\
& Size Sorting & - & 6.73 & 0.0715 & - & - \\
\hline
\end{tabular}

*Note: LRT $p$-values report the results of a likelihood ratio test, which indicates if the inclusion of the independent variables significantly improves the model fit compared to a null model.

results show that site size and size sorting can predict up to $50 \%$ of the noise in median harvests, with less than a $10 \%$ chance that any one variable is producing a false positive. This result confirms the main predictions proposed in this paper and highlight how these two measures of site structure can be used to inform researchers on broader scale patterns in foraging ecology.

In addition to supporting the major predictions, the results from multivariate models suggest that these measures may be more indicative of median than mean returns. Since median values are more robust to skew, this should be true with any resource where returns are characterized by a skewed distribution biased by zeros resulting from failed bouts. These findings also suggest that size sorting may be a clearer indicator of overall foraging yields driven by patch quality than site size may be of in-patch competition driven by the number of foragers. This could result because site size is more a reflection of the number of occupants than the number of foragers, or it could be that the number of foragers within a patch increases cooperation rather than competition, which may lead to greater per capita yields (e.g., Smith, 1991, 792 cf. Bliege Bird et al. 2012b).

\subsection{Applications in Archaeological Contexts 794}

This framework should significantly ex- 795 pand the explanatory role of site structure 796 in archaeological studies of hunter-gatherers. 797 However, these findings will be applicable in 798 archaeological contexts only where at least 799 two conditions are met, one relating to site 800 formation and the other to investigation. 801 First, accurate patterns of material disper- 802 sion will only be preserved in rapid de- 803 positional environments that are impacted 804 by limited post-depositional activity. While 805 this may be rare (e.g., Fanning and Hold- 806 away, 2001), it is not unknown (e.g., En- 807 loe, 2006). Second, adequate reconstruc- 808 tions of site structure will require investiga- 809 tions that excavate large, contiguous expo- 810 sures and carefully record material to cap- 811 ture intra-site variation in their distribution 812 (O'Connell, 1987, 1995). While previous 813 work has cautioned about the extraordinary 814 costs associated with fine-grained analyses 815 of microrefuse (Metcalfe and Heath, 1990), 816 here we show that these interpretations are 817 possible even with relatively coarse-grained 818 
excavation techniques relying on a 1-x-1$\mathrm{m}$ grid and nested 6-mm and 3-mm mesh screens. One final condition to consider concerns whether the activities under investigation were centered around hearths. Hearths provide a focal area for site occupants to center activities (e.g., Binford, 1978b,a) and a durable indicator for archaeologists to center excavations (e.g., Metcalfe and Heath, 1990; Simms and Heath, 1990); as such, the applicability of these insights to archaeological contexts will likely be amplified when hearthcentered activities are under investigation.

Where these criteria are met, including in archaeological contexts in Africa (e.g., Parkington et al., 2009), the Near East (e.g., Maher et al., 2012), Europe (e.g., Enloe, 2006), Asia (e.g., Sakaguchi, 2007), and the Americas (e.g., Bamforth et al., 2005; Burns, 2005; Simms, 1989; Tipps, 1993), examinations of the relative differences in site size and size sorting through time or across space may be used to inform on variation in foraging efficiency and its consequences for subsistence, settlement and mobility. For example, if the suite of resources represented at a site and its size remain constant, a diachronic shift toward greater size sorting may indicate higher environmental productivity, producing higher foraging yields and lower mobility. Or, if the suite of resources represented at a site widens to include lower profitability resources, shifts toward larger sites and/or greater size sorting could be used as supporting evidence of resource intensification (i.e., Boserup, 1965, see Morgan 2015), with more people spending more time in patch taking lower profitability resources. Of course, in any of these circumstances, multiple lines of evidence will be needed to support these findings. Additional elements of site structure, such as the presence or absence of storage features, can also help inform on the duration of occupation (Binford, 1980).

\subsection{Future Ethnoarchaeological Work}

While the findings presented here are en- 864 couraging, future ethnoarchaeological inves- 865 tigations are needed to confirm these results 866 and examine how they vary in different con- ${ }_{867}$ texts. Existing data from extensive stud- 868 ies in Africa (e.g., Yellen, 1977; O'Connell ${ }_{869}$ et al., 1991) and Australia (e.g., Hayden, 870 1979; O'Connell, 1987) could also be used 871 to evaluate some or all of these hypotheses. $\quad 872$ Additional questions may also be approached 873 within this general framework. $\quad 874$

For example, variation in size sorting at 875 longer-term camps may be a function of the 876 ways in which technologies alter cleaning effi- 877 ciency (Metcalfe and Heath, 1990; O'Connell, 878 1987). The costs and benefits of differ- 879 ent cleaning methods and technologies may 880 present a trade-off that can be modeled by ${ }_{881}$ the MVT: with increased duration of occu- ${ }_{882}$ pation, investments in better cleaning tech- 883 nology might be offset by increased cleaning $\quad 884$ efficiency, which should lead to exponential 885 increases in size sorting. This could be tested 886 by examining contexts where hunter-gatherer $\quad 887$ settlement patterns produce some sites occu- 888 pied for short intervals and others occupied 889 for long intervals, both with attendant differ- 890 ences in cleaning technology.

Future work could also use this framework 892 to examine how patterns in site structure 893 vary by gender to reveal differences in the di- 894 vision of foraging labor. Specifically, where 895 women's and men's foraging strategies pro- 896 duce different sites that differ consistently in 897 the number of foragers or in the time spent ${ }_{898}$ foraging, comparisons between sites may re- 899 veal patterns in site size and size sorting 900 that can be used to differentiate women's and 901 men's camps (e.g., O'Connell et al., 1991). 902

The true value of any of this work will 903 be its ability to expand our understanding 904 of site structure from the perspective of a 905 general theory of behavior (O'Connell, 1995). 906 Until additional ethnoarchaeological work is 907 
undertaken to validate and expand theorydriven analyses of site structure, "...archaeologists interested in site structure are stuck with highly speculative predictions and interpretations grounded in some combination of local ethnography, exotic ethnoarchaeology, and their own intuition" (O'Connell, 1993, 24).

\section{Conclusion}

Studies of site structure have remained largely descriptive, even over the past twenty years since O'Connell (1995) illustrated the potential utility of approaching these problems with a general theory of behavior. Here we suggest this is the result of an inherent limitation of site structure given that the behaviors which produce it are not significantly structured by adaptive constraints at the site level. As an alternative, we propose and implement an approach that uses measures of sites structure as proxies for larger scale patterns which should be structured by environmental variability. This is not new in itself (e.g., Binford, 1980), but is novel in linking these proxies to a general theory of behavior that provides deductive, a priori predictions that avoid the problems associated with direct ethnographic analogy (O'Connell, 1993, 1995). This approach does not completely resolve all the issues of site structure - especially those resulting from formation or investigation bias - but we hope this application will inspire future studies of site structure to examine these and develop other avenues to link patterned spatial variation in deposited material to larger ecological patterns of human decisions that can be explained by a general theory of behavior.

\section{Acknowledgment}

We owe a tremendous debt of gratitude to our Martu collaborators for their guid- ance, friendship and support. Curtis Taylor 950 provided instrumental assistance in the im- 951 plementation of this work. Special thanks 952 to Hamza, Chili, Wilson, Roderick, Nyaparu 953 and Nyaparu for the assistance in collecting 954 these data. This paper was originally devel- 955 oped as a presentation in a session honor- 956 ing James F. O'Connell organized by Karen 957 Lupo at the 80th annual meeting of the So- 958 ciety for American Archaeology in San Fran- 959 cisco: thanks to Karen for including us in 960 such a successful event, to all the participants 961 for helpful comments, and to Jim for the in- 962 spiration and lunch. Additionally, thanks to 963 Jim for recognizing the utility of a general 964 theory of behavior and for supporting all of 965 our efforts to match his elegance in their ap- 966 plication to ethnographic and archaeological 967 problems. We are grateful for the support 968 of our colleagues, including Peter Kauha- ${ }_{969}$ nen, Brooke Scelza, Bob and Myrna Tonkin- 970 son, Peter Veth, Fiona Walsh, and especially 971 Sarah Robinson who provided a sounding 972 board for many of these incipient ideas. This 973 paper benefited significantly from comments 974 by Duncan Metcalfe, Kenneth Blake Vernon, 975 Kate Magargal, and two anonymous review- 976 ers. Financial support for this work comes 977 from the National Science Foundation (BCS- 978 0314406, BCS-0850664, DDIG BCS-0915380, 979 BCS-1459880), the Woods Institute for the 980 Environment, Department of Anthropology 981 and Archaeology Center at Stanford Univer- 982 sity.

\section{References Cited}

\section{References}

Altman, J. (2001). Sustainable development 986 options on Aboriginal land: The hybrid 987 economy in the twenty-first century. Center 988 for Aboriginal Economic Policy Research 989 Discussion Paper, 226:1-13. 
Altmann, J. (1974). Observational study of behavior: sampling methods. Behaviour, 91:449-459.

Bamforth, D. B., Becker, M., and Hudson, J. (2005). Intrasite spatial analysis, ethnoarchaeology, and paleoindian land-use on the great plains: the allen site. American $A n$ tiquity, 70:561-580.

Binford, L. (1983). In Pursuit of the Past: Decoding the Archaeological Record. Thames and Hudson, New York.

Binford, L. R. (1978a). Dimensional analysis of behavior and site structure: Learning from an Eskimo hunting stand. American Antiquity, 43:330-361.

Binford, L. R. (1978b). Nunamuit Ethnoarchaeology. Academic Press, New York.

Binford, L. R. (1980). Willow smoke and dogs' tails: Hunter-gatherer settlement systems and archaeological site formation. American Anthropologist, 45:4-20.

Bird, D. W., Bird, R. B., and Parker, C. H. (2005). Aboriginal burning regimes and hunting strategies in Australia's Western Desert. Human Ecology, 33(4):443-464.

Bird, D. W. and Bliege Bird, R. (2005). Martu children's hunting strategies in the Western Desert, Australia. In Hewlett, B. and Lamb, M., editors, Hunter-Gatherer Childhoods: Evolutionary, Developmental $\&$ Cultural Perspectives, pages 129-146. Aldine Transactions, New Brunswick.

Bird, D. W. and Bliege Bird, R. (2010). Competing to be leaderless: food sharing and magnanimity among Martu Aborigines. In Kantner, J. and Vaughn, K., editors, The Emergence Of Leadership: Transitions In Decision Making From SmallScale To Middle-Range Societies. School of American Research, Santa Fe.
Bird, D. W., Bliege Bird, R., and Codding, 1031 B. F. (2009). In pursuit of mobile prey: 1032 Martu hunting strategies and archaeofau- 1033 nal interpretation. American Antiquity, 1034 74(1):3-29.

1035

Bird, D. W. and O'Connell, J. F. (2006). Be- 1036 havioral ecology and archaeology. Jour- 1037 nal of Archaeological Research, 14:143-188. ${ }_{1038}$ 10.1007/s10814-006-9003-6.

1039

Bird, R. B. and Power, E. A. (2015). 1040 Prosocial signaling and cooperation among 1041 Martu hunters. Evolution and Human Be- 1042 havior, 36(5):389-397.

1043

Bliege Bird, R. and Bird, D. W. (2008). Why ${ }_{1044}$ women hunt: risk and contemporary for- 1045 aging in a Western Desert Aboriginal com- 1046 munity. Current Anthropology, 49:655-693. 1047

Bliege Bird, R., Bird, D. W., Codding, B. F., 1048 Parker, C. H., and Jones, J. H. (2008). The 1049 "fire stick farming" hypothesis: Australian 1050 Aboriginal foraging strategies, biodiversity, 1051 and anthropogenic fire mosaics. Proceed- 1052 ings of the National Academy of Sciences, 1053 105(39):14796-14801.

1054

Bliege Bird, R., Codding, B. F., and Bird, 1055 D. W. (2009). What explains differences 1056 in men's and women's production? deter- 1057 minants of gendered foraging inequalities 1058 among Martu. Human Nature, 20:105-129. 1059 10.1007/s12110-009-9061-9.

1060

Bliege Bird, R., Codding, B. F., Kauhanen, 1061 P. G., and Bird, D. W. (2012a). Abo- 1062 riginal hunting buffers climate-driven fire- 1063 size variability in Australia's spinifex grass- 1064 lands. Proceedings of the National Academy 1065 of Sciences, 109:10287-10292.

1066

Bliege Bird, R., Scelza, B., Bird, D. W., ${ }_{1067}$ and Smith, E. A. (2012b). The hierarchy 1068 of virtue: mutualism, altruism and signal- 1069 ing in Martu women's cooperative hunting. 1070 Evolution and Human Behavior, 33:64-78. 1071 
Bliege Bird, R., Taylor, N., Codding, B. F., and Bird, D. W. (2013). Niche construction and Dreaming logic: Aboriginal patch mosaic burning and varanid lizards (Varanus gouldii) in Australia. Proceedings of the Royal Society B., 280:20132297.

Boserup, E. (1965). The Conditions of Agricultural Growth: The Economics of Agrarian Change under Population Pressure. Aldine, Chicago, Illinois.

Broughton, J. M., Cannon, M. D., Bayham, F. E., and Byers, D. A. (2011). Prey body size and ranking in zooarchaeology: theory, empirical evidence and applications from the northern Great Basin. American Antiquity, 76:403-428.

Bui, R., Buliung, R. N., and Remmel, T. K. (2012). aspace: A collection of functions for estimating centrographic statistics and computational geometries for spatial point patterns. v. 3.2.

Burns, J. A. (2005). What about behavior?: Methodological implications for rockshelter excavation and spatial analysis. North American Archaeologist, 26(3):267-282.

Byrd, B. F., Garrard, A. N., and Brandy, P. (2015). Modeling foraging ranges and spatial organization of Late Pleistocene hunter-gatherers in the southern Levant: A least-cost GIS approach. Quaternary International, -:- .

Charnov, E. and Parker, G. A. (1995). Dimensionless invariants from foraging theory's marginal value theorem. Proceedings of the National Academy of Sciences, 92:1446-1450.

Charnov, E. L. (1976). Optimal foraging, the marginal value theorem. Theoretical Population Biology, 9:129-136.
Charnov, E. L., Orians, G., and Hyatt, K. 1111 (1976). Ecological implications of resource 1112 depression. American Naturalist, 110:247- 1113 259.

Codding, B. F. (2012). 'Any Kangaroo?' On 1115 the Ecology, Ethnography and Archaeology 1116 of Foraging in Australia's Arid West. PhD 1117 thesis, Department of Anthropology, Stan- 1118 ford University.

1119

Codding, B. F. and Bird, D. W. (2015). Be- 1120 havioral ecology and the future of archae- 1121 ological science. Journal of Archaeological ${ }_{1122}$ Science, 56:9-20.

Codding, B. F., Bird, D. W., and Bliege Bird, ${ }_{1124}$ R. (2010). Interpreting abundance in- 1125 dices: some zooarchaeological implications 1126 of Martu foraging. Journal of Archaeologi- 1127 cal Science, 37(12):3200-3210.

1128

Codding, B. F., Bliege Bird, R., and Bird, 1129 D. W. (2011). Provisioning offspring and 1130 others: risk-energy trade-offs and gen- 1131 der differences in hunter-gatherer foraging 1132 strategies. Proceedings of the Royal Soci- 1133 ety, B., 278:2502-2509.

1134

Codding, B. F., Bliege Bird, R., Bird, D. W., 1135 and Zeanah, D. W. (2016). Alternative ${ }_{1136}$ Aboriginal economies: Martu livelihoods 1137 in the 21st century. In Codding, B. F. 1138 and Kramer, K. L., editors, Why Forage? ${ }_{1139}$ Hunters and Gatherers in the 21st Century. 1140 School for Advanced Research Press, Santa 1141 Fe and University of New Mexico Press, Al- ${ }_{1142}$ buquerque.

1143

Codding, B. F., Bliege Bird, R., Kauhanen, 1144 P. G., and Bird, D. W. (2014). Con- 1145 servation or co-evolution? intermediate 1146 levels of Aboriginal hunting and burning 1147 have positive effects on kangaroo popula- 1148 tions in Western Australia. Human Ecol- ${ }_{1149}$ ogy, 42:659-669. DOI: 10.1007/s10745-014- 1150 9682-4. 
Cook, S. F. and Treganza, A. E. (1950). The quantitative investigation of Indian mounds: With special reference to the relation ofthe physical components to the probable material culture. University of California Publications in American Archaeology and Ethnology, 40:223-262.

David, N. and Kramer, C. (2001). Ethnoarchaeology in Action. Cambridge University Press.

Enloe, J. G. (2006). Geological processes and site structure: Assessing integrity at a Late Paleolithic open-air site in northern France. Geoarchaeology, 21(6):523-540.

Fanning, P. and Holdaway, S. (2001). Stone artifact scatters in western NSW, Australia: Geomorphic controls on artifact size and distribution. Geoarchaeology, 16(6):667-686.

Faraway, J. (2006). Extending the Linear Model with R: Generalized Linear, Mixed Effects and Nonparametric Regression Models. Chapman and Hall, New York.

Gould, R. A. (1967). Notes on the hunting, butchering, and sharing of game among the Ngatatjara and their neighbors in the West Australian desert. Kroeber Anthropological Papers, 36:41-66.

Gould, R. A. (1969). Subsistence behaviour among the Western Desert Aborigines of Australia. Oceana, 4:253-274.

Gould, R. A. (1977). Puntutjarpa Rockshelter and the Australian Desert Culture, volume 54 of Anthropological Papers. The American Museum of Natural History.

Hayden, B. (1979). Palaeolithic Reflections: lithic technology and ethnographic excavation among Australian Aborigines.
Australian Instittue of Aboriginal Studies, 1191 Canberra.

Hayden, B. and Cannon, A. (1983). Where 1193 the garbage goes: Refuse disposal in the 1194 Maya Highlands. Journal of Anthropologi- 1195 cal Archaeology, 2:117-163.

1196

Hill, M. G., Rapson, D. J., Loebel, T. J., and ${ }_{1197}$ May, D. W. (2011). Site structure and ac- 1198 tivity organization at a Late Paleoindian 1199 base camp in Western Nebraska. Ameri- 1200 can Antiquity, 76(4):752-772.

1201

Kelly, R. L., Surovell, T. A., Shuman, B. N., 1202 and Smith, G. M. (2013). A continuous 1203 climatic impact on Holocene human pop- 1204 ulation in the Rocky Mountains. Proceed- 1205 ings of the National Academy of Sciences, 1206 110(2):443-447.

1207

Kent, S. (1991). The relationship between ${ }_{1208}$ mobility strategies and site structure. In 1209 Kroll, E. and Price, T. D., editors, The 1210 Interpretation of Spatial Patterning Within 1211 Stone Age Archaeological Sites, pages 33- 1212 59. Plenum Press, New York.

1213

Kent, S. (1992). Studying variability in the 1214 archaeological record: An ethnoarchaeo- 1215 logical model for distinguishing mobility 1216 patterns. American Antiquity, 57:635-660. 1217

Kent, S. and Vierich, H. (1989). The myth 1218 of ecological determinism-anticipated mo- 1219 bility and site spatial organization. In 1220 Kent, S., editor, Farmers as Hunters- 1221 Implications of Sedentism, pages 96-134. ${ }_{1222}$ Cambridge University Press.

1223

Maher, L., Richter, T., Stock, J. T., Mac- ${ }_{1224}$ Donald, D., Jones, M., and Martin, L. 1225 (2012). Twenty thousand-year-old huts 1226 at a hunter-gatherer settlement in eastern 1227 Jordan. PLoS One, 7(2):1-10. 
Meehan, B. (1982). Shell Bed to Shell Midden. Australian Instittue of Aboriginal Studies, Canberra.

Metcalfe, D. and Heath, K. M. (1990). Microrefuse and site structure: The hearths and floors of the Heartbreak Hotel. American Antiquity, 55:781-796.

Morgan, C. (2012). Modeling modes of hunter-gatherer food storage. American Antiquity, 77:714-736.

Morgan, C. (2015). Is it intensification yet? current archaeological perspectives on the evolution of hunter-gatherer economies. Journal of Archaeological Research, 10.1007/s10814-014-9079-3:1-51.

O'Connell, J., Hawkes, K., and Jones, N. (1991). Distribution of refuse-producing activities at Hadza residential base camps: implications for analyses of archaeological site structure. In Kroll, E. and Price, T., editors, The interpretation of archaeological spatial patterning, pages 61-76. Plenum, New York.

O'Connell, J. F. (1977). Room to move: Contemporary Alyawara settlement patterns and their implications for Aboriginal housing policy. Mankind, 11:119-131.

O'Connell, J. F. (1987). Alyawara site structure and its archaeological implications. American Antiquity, 52:74-108.

O’Connell, J. F. (1993). What can Great Basin archaeologists learn from the study of site structure? an ethnoarchaeological perspective. Utah Archaeology, 6:7-26.

O’Connell, J. F. (1995). Ethnoarchaeology needs a general theory of behavior. Journal of Archaeological Research, 3:205-255. 10.1007/BF02231450.
O'Connell, J. F. and Marshall, B. (1989). ${ }_{1267}$ Analysis of kangaroo body part trans- 1268 port among the Alyawara of central Aus- 1269 tralia. Journal of Archaeological Science, 1270 16(4):393-405.

1271

Ohara, R. B. and Kotze, D. J. (2010). Do 1272 not log-transform count data. Methods in 1273 Ecology and Evolution, 1(2):118-122. 1274

Orians, G. H. and Pearson, N. E. (1979). ${ }_{1275}$ On the theory of central place foraging. 1276 In David J. Horn, G. R. S. and Mitchell, 1277 R. T., editors, Analysis of Ecological Sys- 1278 tems, pages 155-177. Ohio State University ${ }_{1279}$ Press.

1280

Parkington, J., Fisher Jr, J. W., and Tonner, 1281 T. W. (2009). "The fires are constant, the ${ }_{1282}$ shelters are whims": A feature map of later ${ }_{1283}$ stone age campsites at the Dunefield Mid- 1284 den Site, Western Cape Province, South 1285 Africa. The South African Archaeological ${ }_{1286}$ Bulletin, 64:104-121.

1287

$\mathrm{R}$ Core Team (2015). R: A Language ${ }_{1288}$ and Environment for Statistical Comput- 1289 ing. R Foundation for Statistical Comput- 1290 ing, Vienna, Austria. v.3.2.3 (2015-12-10, 1291 Wooden Christmas-Tree)

1292

Sakaguchi, T. (2007). Refuse patterning and ${ }_{1293}$ behavioral analysis in a pinniped hunting 1294 camp in the late Jomon Period: A case ${ }_{1295}$ study in layer $\mathrm{V}$ at the Hamanaka 2 site, 1296 Rebun Island, Hokkaido, Japan. Journal of 1297 Anthropological Archaeology, 26(1):28-46. ${ }_{1298}$

Scelza, B. (2009). The grandmaternal niche: 1299 Critical caretaking among Martu Aborig- 1300 ines. American Journal of Human Biology, 1301 21:448-454.

1302

Scelza, B. (2010). Father's presence speeds 1303 the social and reproductive careers of sons. 1304 Current Anthropology, 5:295-303. 
Scelza, B. and Bliege Bird, R. (2008). Group structure and female cooperative networks in Australias Western Desert. Human $\mathrm{Na}$ ture, 19:231248.

Shennan, S., Downey, S. S., Timpson, A., Edinborough, K., Colledge, S., Kerig, T., Manning, K., and Thomas, M. G. (2013). Regional population collapse followed initial agriculture booms in mid-holocene europe. Nature Communications, 4:1-8.

Simms, S. R. (1989). The structure of the bustos wickiup site, eastern nevada. Journal of California and Great Basin Anthropology, 11(1):2-34.

Simms, S. R. and Heath, K. M. (1990). Site structure of the Orbit Inn: An application of ethnoarchaeology. American Antiquity, 55:797-813.

Smith, E. A. (1991). Inujjuamiut Foraging Strategies: Evolutionary Ecology of an Arctic Hunting Economy. Aldine de Gruyter, New York.

Speth, J. D. (2010). The Paleoanthropology and Archaeology of Big-Game Hunting. Springer.

Speth, J. D., Meignen, L., Bar-Yosef, O., and Goldberg, P. (2012). Spatial organization of Middle Paleolithic occupation $\mathrm{X}$ in Kebara Cave (Israel): Concentrations of animal bones. Quaternary International, 247:85-102.

Stanner, W. E. H. (1965). Aboriginal territorial organization: Estate, range, domain and regime. Oceania, 36:1-26.

Stevens, N. E. and McElreath, R. (2015). When are two tools better than one? mortars, millingslabs, and the California acorn economy. Journal of Anthropological Archaeology, 37:100-111.
Surovell, T. A. (2012). Toward a behavioral 1345 ecology of lithic technology: cases from $\mathrm{Pa}^{-}{ }_{1346}$ leoindian archaeology. University of Ari- 1347 zona Press.

Tinbergen, N. (1963). On aims and methods 1349 in ethology. Zeitschrift für Tierpsychologie, 1350 20:410-433.

Tipps, B. L. (1993). Investigating the spa- 1352 tial structure of lithic scatter sites from an 1353 ethnoarchaeological perspective: Examples ${ }_{1354}$ from Utah and Nevada. Utah Archaeology, 1355 6:57-71.

1356

Tonkinson, R. (1993). The Mardu Aborigines: 1357 Living the Dream in Australias Desert. ${ }_{1358}$ Holt, Rinehart \& Winston, New York, 2nd 1359 edition.

Veth, P. and Walsh, F. (1988). The con- 1361 cept of "staple" plant foods in the Western ${ }_{1362}$ Desert region of Western Australia. Aus- 1363 tralian Aboriginal Studies, 2:19-25.

1364

Walsh, F. (1987). Patterns of plant use by 1365 Martujarra Aborigines. Master's thesis, 1366 University of Western Australia. Unpub- ${ }_{1367}$ lished.

1368

Walsh, F. (2008). To hunt and to hold: 1369 Martu Aboriginal people's uses and knowl- 1370 edge of their country, with implications 1371 for co-management in Karlamilyi (Rudal 1372 River) National Park and the Great Sandy 1373 Desert, Western Australia. PhD thesis, 1374 School of Social and Cultural Studies (An- 1375 thropology) and School of Plant Biology 1376 (Ecology), The University of Western Aus- ${ }_{1377}$ tralia.

1378

Whelan, C. S., Whitaker, A. R., Rosenthal, 1379 J. S., and Wohlgemuth, E. (2013). Hunter- 1380 gatherer storage, settlement and the oppor- 1381 tunity costs of women's foraging. American 1382 Antiquity, 78:662-678. 
Williams, A. N., Veth, P., Steffen, W., Ulm, S., Turney, C. S., Reeves, J. M., Phipps, S. J., and Smith, M. (2015). A continental narrative: Human settlement patterns and Australian climate change over the last 35,000 years. Quaternary Science Reviews, 123:91-112.

Winterhalder, B., Kennett, D. J., Grote, M. N., and Bartruff, J. (2010). Ideal free settlement of California's Northern Channel Islands. Journal of Anthropological Archaeology, 29:469-490.

Yellen, J. (1977). Archaeological Approaches to the Present. Academic Press, New York.

Zeanah, D. W., Codding, B. F., Bird, D. W., Bird, R. B., and Veth, P. M. (2015). Diesel and damper: Changes in seed use and mobility patterns following contact amongst the Martu of Western Australia. Journal of Anthropological Archaeology, 39:51-62. 
